\title{
An Overview of the Development of New Vaccines for Tuberculosis
}

\author{
E. Whitlow ${ }^{1}$, A. S. Mustafa ${ }^{2}$ and S. N. M. Hanif ${ }^{1, *}$ \\ 1 Department of Basic Sciences, Kentucky College of Osteopathic Medicine, University of Pikeville, \\ Pikeville, KY 41501, USA; emmawhitlow@upike.edu \\ 2 Department of Microbiology, Faculty of Medicine, Kuwait University, Safat 13110, Kuwait; \\ abusalim@hsc.edu.kw \\ * Correspondence: shumailahanif@upike.edu
}

Received: 1 September 2020; Accepted: 2 October 2020; Published: 5 October 2020

\begin{abstract}
Currently, there is only one licensed vaccine against tuberculosis (TB), the Bacillus Calmette-Guérin (BCG). Despite its protective efficacy against TB in children, BCG has failed to protect adults against pulmonary $\mathrm{TB}$, lacks therapeutic value, and causes complications in immunocompromised individuals. Furthermore, it compromises the use of antigens present in the purified protein derivate of Mycobacterium tuberculosis in the diagnosis of TB. Many approaches, e.g., whole-cell organisms, subunit, and recombinant vaccines are currently being explored for safer and more efficacious TB vaccines than BCG. These approaches have been successful in developing a large number of vaccine candidates included in the TB vaccine pipeline and are at different stages of clinical trials in humans. This paper discusses current vaccination strategies, provides directions for the possible routes towards the development of new $\mathrm{TB}$ vaccines and highlights recent findings. The efforts for improved TB vaccines may lead to new licensed vaccines capable of replacing/supplementing BCG and conferring therapeutic value in patients with active/latent TB.
\end{abstract}

Keywords: vaccines; Mycobacterium tuberculosis; tuberculosis; BCG; new vaccines

\section{Introduction}

Tuberculosis (TB), a disease caused by Mycobacterium tuberculosis (Mtb), is the leading cause of death due to an infectious agent in the world [1]. Mtb infection causes active TB disease in 10 million people and leads to 1.5 million deaths annually [1]. Furthermore, about a quarter of the world's population (about 2 billion people) are latently infected with $\mathrm{TB}$, which becomes a pool for active TB cases later in life [2]. Currently, there is only one licensed vaccine against TB, i.e., Mycobacterium bovis Bacillus Calmette-Guérin (BCG) [3], and it is one of the most widely used vaccines globally [4]. Each year, BCG is given to about 100 million children worldwide [5]. Vaccination with BCG prevents the most severe forms of childhood TB by reducing the risk of meningeal and miliary TB by $85 \%$ and TB-associated deaths by $66 \%$ [6]. The BCG vaccine protects children against TB for up to 10 years, but its efficacy declines with each subsequent year [7]. Additionally, it does not provide protection against adult pulmonary TB [8] and lacks any additional benefit upon revaccination of healthy and active TB cases [8]. Furthermore, there are safety issues related to the BCG vaccine, as it is a live attenuated vaccine with a risk of becoming virulent [8]. The BCG vaccine was first produced in 1921, and because of its shortcomings, a more effective and safer vaccine is needed to replace or supplement it [9].

Furthermore, another worldwide epidemic, type 2 diabetes, is associated with a 2-4 times increased risk of developing active TB [10], and a known glucose control medication lowers the immune response to exacerbate the risk further [11]. This, along with the emergence of drug-resistant $\mathrm{TB}$, has increased 
the necessity for developing a better vaccine for TB [9]. In addition, an effective vaccine against TB may also protect against asthma, another non-infectious disease of high global prevalence [12].

Many vaccines are in the pipeline (Tables 1-3) with an aim to produce a new vaccine for $\mathrm{TB}$, and different strategies include replacing $B C G$, boosting $B C G$, and therapeutic use [13]. Different approaches are explored as pre- and post-exposure vaccines for TB. This paper aims to give an overview of the TB vaccine candidates in the pipeline, discusses current vaccination strategies, and highlights recent findings.

\section{Status of Current TB Vaccine: BCG}

The only currently licensed vaccine against pulmonary and extrapulmonary TB is the live attenuated BCG vaccine. It was originally derived from the pathogenic Mycobacterium bovis that causes TB primarily in cows [14]. To attenuate its pathogenicity, two French scientists, Calmette and Guerin, cultured M. bovis on an artificial medium in vitro for 13 years (1908-1921) and a total of 231 passages. The resulting organism, BCG, did not cause TB lesions in various animal models but was immunogenic and protected the immunized animals against challenges with M. bovis [3]. Since 1921, the BCG vaccine has been used in infants and children and is effective in providing protection against childhood TB [15], avoiding 120,000 childhood deaths per year [16]. However, it fails to protect against adult pulmonary $\mathrm{TB}$, the major manifestation of the disease [8]. For example, although high-incidence nation China has an overwhelming BCG vaccine coverage, three-quarters of TB is estimated to occur in the 45-year-old or older population [16]. BCG's decline in efficacy after 10 years is an additional problem for countries with a high incidence of $\mathrm{TB}$, as BCG vaccination occurs at birth, leaving people at risk later in life when they are most vulnerable [17]. In fact, the elderly have been shown to have a higher prevalence of TB across all age groups [9].

The BCG vaccine also poses a risk to immunocompromised individuals [18,19]. Those with primary immunodeficiencies are prone to develop severe vaccine-derived complications [18]. Additionally, BCG vaccination of HIV-exposed but uninfected infants resulted in reduced BCG-specific T-cell proliferation and production of lower concentrations of protective cytokines IFN- $\gamma$ and TNF- $\alpha$, compared to healthy infants [19]. The results further showed a delay in immune system maturation of HIV-exposed uninfected infants and hence resulted in a higher risk for developing TB [19]. Furthermore, BCG vaccination of HIV-infected infants and children has the risk of causing a TB-like disseminated disease known as BCG-osis [3]. In addition, BCG is a preventative pre-exposure or prophylaxis vaccine and is not effective as a therapeutic vaccine against post-exposure active and latent TB [14].

BCG also poses a complication for the diagnosis of active as well as latent TB by using the antigenic preparation of Mtb known as purified protein derivative (PPD) in Mantoux or tuberculin skin test (TST). In this test, PPD is injected intradermally to evaluate cell-mediated immunity in response to Mtb antigens. The intradermal injection of PPD produces a type IV hypersensitivity reaction, and is used for diagnosis of both active and latent TB [20]. Although the World Health Organization has recommended the use of this test for diagnosing tuberculosis in low-resource settings [21], BCG vaccination compromises PPD's diagnostic value due to low specificity. This is because PPD is a crude mixture of several hundred proteins of $M$. tuberculosis and many of them are present in BCG as well, leading to antigenic cross-reactivity and causing a high rate of false positivity [22]. A reduction in the antigen cross-reactivity is required for test accuracy; however, limited research and discussions have addressed this problem.

\section{Immune Characteristics and Markers for Mtb}

The complexities of Mtb infection in humans create challenges in finding targets of the immune reaction to the pathogen. Mtb bacilli first enter the lungs in aerosol droplets. Due to the innate immune response, macrophages ingest the bacteria and recruit other immune cells [8]. Neutrophils, Delta T cells, NK cells, and $\mathrm{CD} 4^{+} \mathrm{T}$ cells are activated to control the infection, leading to the formation of a 
granuloma [9]. The granuloma contains a small number of bacilli that may contribute to the reactivation of disease later in life [23]. In the majority of cases, $\mathrm{CD} 4^{+} \mathrm{T}$ cells will control the bacteria from further infection; however, in some cases, the infection can reactivate and develop to an acute, chronic, or extrapulmonary infection [9]. The disease is efficient in evading the immune response and can be in the latent stage for years before symptoms are expressed [9]. Reasons why most people exposed to Mtb do not develop TB is not well understood [13].

The cytokines IL-12, IL- 8 , IFN- $\gamma$, TNF- $\alpha$, TGF- $\beta$, IL-17, and memory T cells have been shown to be active in the immune response against TB [24]. While these markers are known to be involved in the immune response, Mtb does not have a known validated immune correlate of protection (COP). Without this, it requires years to collect data for study endpoints [13]. Satti and McShane [25] stated that COP would allow vaccines to be optimized and explored based on their match with the proven immune response, leading to licensure of vaccines. The COP could help explain the vaccine MVA85A's dismal response in phase 2. In previous clinical trials, the vaccine produced high levels of CD4 ${ }^{+}$ $\mathrm{T}$ cell response but did not produce a robust response in the phase 2 trial [26]. Although $\mathrm{CD}^{+} \mathrm{T}$ cells play a predominant role in protective TB immunity, strategies that boost $\mathrm{CD}^{+}$function also enhance vaccine efficacy [26]. In a nonhuman primate model of tuberculosis disease, depletion of $\mathrm{CD}^{+} \mathrm{T}$ cells in immunized monkeys led to reduced protection. Similarly, $\mathrm{CD}^{+} \mathrm{T}$ cell depletion in M. tuberculosis-infected and then antibiotic-treated monkeys led to increased susceptibility to reinfection, indicating their importance in conferring immunity in a vaccination or natural infection setting. Human $\mathrm{CD}^{+} \mathrm{CCR}^{-} \mathrm{CD}^{-} 5 \mathrm{RA}^{+}$effector memory T cells exhibit significant anti-mycobacterial activity [26].

\section{Vaccine Approaches}

Based on the current understanding of $\mathrm{Mtb}$, there are a number of strategies for the application of new vaccines, i.e., preventive pre-exposure (for uninfected individuals/infants), preventive post-exposure (for latent TB/adolescents and adults), and therapeutic (for active TB) [27]. Pre-exposure vaccines either aim to induce a more robust protective immune response than BCG in order to prevent disease or produce a faster response, so the infection is not established [8]. The post-exposure vaccine strategy aims to either induce a robust and long-lasting response to prevent disease reactivation or eliminate latent $\mathrm{TB}$ by inducing sterilizing immunity so that bacteria are not able to be reactivated later and lead to active TB [8]. The only currently licensed vaccine, BCG, follows the preventative pre-exposure approach. An additional approach for categorizing vaccines in preclinical and clinical trials places vaccines in their biochemical forms: live attenuated, inactivated, adjuvanted protein subunit, and recombinant. Some vaccines have also been created as a boost to BCG [28,29], and others have used unique modes of administration in an attempt to boost immune response [30].

There are currently at least 23 vaccine candidates in clinical trials in humans, as shown in Table 1 and Table 2. The recent developments focus on live attenuated, inactivated, subunit and recombinant vaccine types; and various antigens and adjuvant combinations are being tested in the case of subunit vaccines.

Table 1. Live attenuated, inactivated, and subunit/adjuvant vaccines in clinical trials.

\begin{tabular}{cccc}
\hline Vaccine & Vaccine Type & Phase & NCT Number or Author \\
\hline MTBVAC & Live attenuated & Two trials recruiting for & NCT03767946; NCT03152903 \\
phase 3 & Phase 2a not yet & NCT02711735 \\
recruiting & Inactivated & Two phase 3 trials & Bourinbaiar, A.S., et al. [31] \\
M. Vaccae based & Inactivated & Two phase 3 trials & NCT00265226; NCT00341328 \\
M. indicus pranii (MIP) & Inactivated & Phase 1 & Gong, W., et al. [32] \\
M. smegmatis & Inactivated & &
\end{tabular}


Table 1. Cont.

\begin{tabular}{cccc}
\hline Vaccine & Vaccine Type & Phase & NCT Number or Author \\
\hline DAR-901 & Inactivated & Phase 2a & NCT02712424 \\
M72/AS01E & Subunit/adjuvanted & Phase 2b completed & NCT01755598 \\
H4:IC31 & Subunit/adjuvanted & Phase 2b & NCT02075203 \\
(AERAS 404) & Subunit/adjuvanted & Phase 2a ongoing; & NCT03512249 \\
H56:IC31 & Subunit/adjuvanted & Phase 2a & NCT02465216 \\
ID93 + GLA-SE & Subunit/adjuvanted & Phase 2a & NCT03878004 \\
GamTBvac & Subunit/adjuvanted & Phase 1 recruitment & NCT03026972; NCT04239313 \\
AEC/BCO2 & Subunit/adjuvanted & Phase 2b & NCT00397943 \\
Mtb72F/AS02 & &
\end{tabular}

\section{Live Attenuated Vaccines}

The vaccines using the live attenuated approach contain whole Mtb in its weakened or altered form [33]. MTBVAC is the only live attenuated vaccine undergoing clinical trials in humans, and currently, two trials for the vaccine are recruiting for phase 3 (NCT03767946; NCT03152903) (Table 1). This vaccine is designed as a replacement for BCG and as an immunotherapeutic agent [13]. This vaccine is based on one of the seven phylogenetic branches (L1-L7) of the M. tuberculosis complex (MTBC) known as lineage 4 (L4). MTBVAC is derived from a clinical M. tuberculosis isolate Mt103 after deletion of two virulence-related genes $p h o P$ and $f a d D 26$. Safety studies in immunocompromised mice with severe combined immunodeficiency (SCID) have shown that MTBVAC is more attenuated than BCG [34]. Preclinical studies have also been completed with attenuated $M$. tuberculosis belonging to two other strains of MTBC i.e., L2 (MTBVAC-L2) and L3 (MTBVAC-L3), two of the three modern lineages of $M$. tuberculosis. The study demonstrated that vaccination with MTBVAC, MTBVAC-L2, and MTBVAC-L3 had similar or superior protection compared to BCG in immunocompetent mice, when the immunized mice were challenged with the three representative strains. This study shows the potential of MTBVAC to protect against the globally diverse strains of MTBC [34]. MTBVAC has also been used as a vector to make a dual TB-HIV vaccine known as MTBVAC.HIVA ${ }^{2 a u x o}$ [35]. In this study, a recombinant strain was constructed by inserting HIV clade-1 A immunogen HIVA into the parental strain MTBVAC. This TB-HIV vaccine provided similar protective efficacy to the parental MTBVAC strain against Mtb challenge in mice. Additionally, the study showed an increased safety profile of MTBVAC.HIVA ${ }^{2 a u x o}$ in comparison with BCG and MTBVAC [35], showing promise for immunosuppressed individuals who are at risk of severe infection or death due to unregulated pathogen replication [32].

\section{Inactivated Vaccines}

Inactivated vaccines are often considered safer than live vaccines since they do not contain any infectious particles. However, immunogenicity is much weaker than live vaccines and may require multiple doses [32]. These vaccines have been used for both pre- and post-exposure strategies [27]. Among the inactivated vaccines is RUTI, which contains detoxified and fragmented M. tuberculosis cells in liposomes (Table 1). The strategy of inducing an immune response and protection by inactivated organisms belonging to non-pathogenic and environmental mycobacterial species is also in clinical trials, including M. vaccae, M. Indicus pranii (MIP), and M. obunese (DAR-901) (Table 1).

A phase $2 b$ vaccine, RUTI, has exhibited significant humoral and cellular immune responses against antigens expressed in actively growing and latent bacilli [36]. It has shown efficacy in controlling latent TB in experimental animals, i.e., mice, goats, guinea pigs and mini pigs [37], and the RUTI and M. vaccae are being used as therapeutic vaccines to reduce drug treatment duration for patients with active TB [36,38,39]. 
A recent study, using an ex vivo mycobacterial growth inhibition assay (MGIA), has shown RUTI vaccine-induced inhibition in mycobacterial counts and a significant shift towards Ly6C monocyte phenotype in the spleens of immunized mice [40]. Additionally, the vaccination of mice with RUTI upregulated the expressions of $\mathrm{Ly} 6 \mathrm{C}^{-}$related mRNA transcripts in splenocytes, producing a monocyte phenotype shift from $\mathrm{LyC}^{+}[40]$. Ly $6 \mathrm{C}^{-}$monocytes have been shown to have an anti-inflammatory role [41], whereas $\mathrm{Ly} \mathrm{C}^{+}$monocytes are proinflammatory [41]. Therefore, the RUTI vaccine may show a more balanced immune response.

\section{Subunit/Adjuvanted Vaccines}

In comparison to whole pathogen vaccines, subunit vaccines contain selected parts of the pathogen. While this is generally a safer approach, it can produce a less robust immune response [32]. Therefore, to increase efficacy, subunit vaccines are often administered with an adjuvant [8]. Subunit/adjuvanted vaccines are an active area of research (Tables 2 and 3) and combinations are often noted as antigen:adjuvant. Since Mtb expresses around 4000 proteins [24], there are many possibilities for immune targets. Common secreted proteins used in subunit vaccines include ESAT6, MPT64, Ag85B, and Ag85A because of their different expression profiles with those either actively infected with TB or with latent TB [24]. Other proteins identified with high immunogenicity include Rv1031, Rv1198, Rv2016, Rv3874, Rv3875, Rv2031c [42,43], Rv3620 [44], PPE39 [45], and A60 complex [46]. Mtb antigens are expressed at different stages of infection; for example, ESAT-6 is always expressed, but Ag85B is mainly expressed early in infection [47]. This poses a challenge for creating a vaccine that produces enough cell stimulation. $\mathrm{H} 56$ is an example of a protein fusion that stimulates immune responses to antigens expressed at different stages of $\mathrm{Mtb}$ infection. It is a combination of Ag85B, ESAT-6, and Rv660c. In a recent preclinical trial, the vaccine H56: CAF01 has shown activation of both innate and adaptive immunity in mice [48]. This study and others showed hope for new subunit delivery strategies [49].

Aluminum-based adjuvants are primary adjuvants used in vaccines to drive a humoral response. Humoral immunity is not considered to have a major role in protection against Mtb, as it is an intracellular pathogen [9], therefore novel adjuvants may be useful to induce protective Th1 responses [50]. Current adjuvants used in Mtb vaccines include IC31, GLA-SE, AS01E, QS21, CFA01, and DPC [24].

An exciting study with subunit vaccine H4: IC31 was performed in adolescents in a high-risk setting for TB to assess its efficacy in reducing $M$. tuberculosis-specific immune response (an indicator of active TB) in individuals immunized with BCG in neonatal age [51]. The results were compared with BCG revaccination. All the participants had negative results for $M$. tuberculosis-specific immune response as determined by quantifying the concentration of IFN- $\gamma$ secreted by using the QuantiFERON-TB Gold In-tube assay (QFT). QFT conversion, shown by the authors as having a higher risk of progression to TB, was determined in both H4: IC31 vaccinated group and BCG revaccinated group. BCG revaccination reduced the rate of QFT conversion (with an efficacy of 45\% and 95\% CI 6-68) compared to the H4: IC31 (efficacy of 31\%, 95\% CI 16-58) [51]. This study renewed interest in the revaccination with BCG, which had previously been accepted as having no effect $[7,14]$.

In another study, a phase $2 \mathrm{~b}$ clinical trial, the subunit vaccine M72/AS01E prevented pulmonary TB in adults already infected with $\mathrm{Mtb}$ with an efficacy of 54\% [52]. In human studies with six candidate TB vaccines, i.e., MVA85A, AERAS-402, H1: IC31, M72/AS01E, ID93 + GLA-SE, and BCG, M72/AS01E was found to induce higher memory Th1-cytokine expressing CD4 ${ }^{+}$T-cell memory responses [53]. The ability of M72/AS01E to induce the highest memory $\mathrm{CD}^{+} \mathrm{T}$ cell response demonstrates the best vaccine take because the induction of these cells correlates with protective immunity in TB [53].

\section{Recombinant Vaccines}

Recombinant vaccines are produced using the techniques of genetic engineering. In brief, a piece of DNA encoding an antigen of $\mathrm{Mtb}$ is inserted into an appropriate vector to transform either a bacterial, 
mammalian, or yeast cell. The recombinant vector produces the antigen in large quantities in those cells [54]. Because the recombinant antigen can also be purified, the purified antigen can be used as a subunit vaccine to stimulate the immune response and avoid some of the potential concerns of other types of vaccines, such as whole-cell vaccines [55].

Recombinant vaccines (Tables 2 and 3) can be placed into groups based on the type of organism used to express Mtb antigens: live mycobacterial, live bacterial, and live viral vaccines. In live mycobacterial vaccines, bacteria such as $M$. bovis BCG, $M$. vaccae, and $M$. smegmatis have been used as vectors. $M$. bovis BCG is commonly used as an expression vector due to its stability, cost-effectiveness, and non-specific immune stimulation [36,56,57]. Another recombinant bacterial vaccine is Pnz8149-ag85a/NZ3900 which uses $L$. lactis as a vector. This recombinant vaccine is at a preclinical stage, and it was able to induce both cellular and antibody responses after mucosal immunization in mice [58]. Many other recombinant bacterial vaccines are in preclinical stages (Table 3).

Table 2. Recombinant vaccines in clinical trials.

\begin{tabular}{|c|c|c|c|}
\hline Vaccine & Vector Type & Phase & NCT Number or Author \\
\hline VPM1002 & $\begin{array}{l}\text { Recombinant } \\
\text { mycobacterial }\end{array}$ & $\begin{array}{l}\text { Phase } 2 \text { completed, recruiting } \\
\text { for phase } 3 \text {; phase } 2 / 3\end{array}$ & NCT04351685; NCT03152903 \\
\hline Aeras-402 & $\begin{array}{l}\text { Recombinant } \\
\text { mycobacterial }\end{array}$ & Two phase $2 b$ trials & NCT02414828; NCT01198366 \\
\hline rBCG30 & $\begin{array}{l}\text { Recombinant } \\
\text { mycobacterial }\end{array}$ & Phase 1; preclinical in mice & $\begin{array}{c}\text { Yadav, J., et al. [9] } \\
\text { Kaushik, A., et al. [59] }\end{array}$ \\
\hline MVA85A/AERAS-485 & $\begin{array}{l}\text { Recombinant live } \\
\text { viral vectored }\end{array}$ & $\begin{array}{l}\text { Two phase } 2 \mathrm{a} \\
\text { trials completed }\end{array}$ & NCT00953927; NCT01151189 \\
\hline Ad35/AERAS-402 & $\begin{array}{l}\text { Recombinant live } \\
\text { viral vectored }\end{array}$ & Phase 1 recruiting & NCT01683773 \\
\hline Ad5Ag85A & $\begin{array}{l}\text { Recombinant live } \\
\text { viral vectored }\end{array}$ & Phase 1 recruiting & NCT02337270 \\
\hline TB/FLU-04L & $\begin{array}{l}\text { Recombinant live } \\
\text { viral vectored }\end{array}$ & Phase 2a & NCT02501421 \\
\hline ChAdOx1.85A & $\begin{array}{l}\text { Recombinant live } \\
\text { viral vectored }\end{array}$ & Phase 1 & NCT04121494 \\
\hline $\begin{array}{l}\text { ChAdOx1.85A + } \\
\text { MVA85A }\end{array}$ & $\begin{array}{l}\text { Recombinant live } \\
\text { viral vectored }\end{array}$ & Phase 1 & NCT03681860 \\
\hline $\begin{array}{l}\text { ChAd3M72 + } \\
\text { M72/AS01E }\end{array}$ & $\begin{array}{l}\text { Recombinant live } \\
\text { viral vectored }\end{array}$ & Phase 1 & Gong, W., et al. [32] \\
\hline
\end{tabular}

Table 3. Current vaccines in preclinical studies.

\begin{tabular}{|c|c|c|c|}
\hline Vaccine & Vaccine Type & Description & Author \\
\hline $\begin{array}{l}\text { M. tuberculosis H37Rv } \\
\Delta \text { leuD } \Delta \text { panCD strain }\end{array}$ & Live & $\begin{array}{l}\text { Strain used as a TB infection model } \\
\text { in G. mellonella }\end{array}$ & $\begin{array}{l}\text { Asai, M., } \\
\text { et al. [60] }\end{array}$ \\
\hline H56:CAF01 & Subunit/Adjuvanted & $\begin{array}{l}\text { Vaccination strategy of priming and } \\
\text { mucosal pull immunization and } \\
\text { analysis with uptake of H56/CAF01 }\end{array}$ & $\begin{array}{l}\text { Thakur, A., } \\
\text { et al. [46] }\end{array}$ \\
\hline H64:CAF01 & Subunit/Adjuvanted & Protein fusion vaccine & $\begin{array}{l}\text { Stockdale, L. \& } \\
\text { Fletcher, H. [13] }\end{array}$ \\
\hline CysVac2/AdVax & Subunit/Adjuvanted & $\begin{array}{l}\text { CysVac } 2 \text { contains Ag85B and CysD; } \\
\text { promotes generation of } \mathrm{CD}^{+} \mathrm{T} \text { cells }\end{array}$ & $\begin{array}{l}\text { Counoupas, C., } \\
\text { et al. [61] }\end{array}$ \\
\hline BCG-PSN & Subunit/Adjuvanted & $\begin{array}{l}\text { BCG polysaccharide and nucleic } \\
\text { acid injection }\end{array}$ & $\begin{array}{l}\text { Yan, Q., } \\
\text { et al. [62] }\end{array}$ \\
\hline LT70 & Subunit/Adjuvanted & $\begin{array}{l}\text { Induced humoral and cell mediated } \\
\text { immunity and higher protective } \\
\text { efficacy than BCG }\end{array}$ & $\begin{array}{l}\text { Liu, X., } \\
\text { et al. [63] }\end{array}$ \\
\hline rBCG:LTAK63 & Recombinant & $\begin{array}{l}\text { Subunit vaccine with LTAK63 } \\
\text { adjuvant; lower levels of LTAK } 63 \\
\text { created stronger immune response }\end{array}$ & $\begin{array}{l}\text { Carvalho Dos Santos, } \\
\text { C., et al. [64] }\end{array}$ \\
\hline $\mathrm{rBCG}(\Delta)$ ais1/zmpl & Recombinant & Recombinant BCG & Yadav, J., et al. [9] \\
\hline
\end{tabular}


Table 3. Cont.

\begin{tabular}{|c|c|c|c|}
\hline Vaccine & Vaccine Type & Description & Author \\
\hline BCG-ZMPI & Recombinant & $\begin{array}{l}\text { Recombinant live } \\
\text { mycobacterial, lacking } \\
\text { zmp1 gene }\end{array}$ & $\begin{array}{l}\text { Stockdale, L } \\
\text { \& Fletcher, H. [13] }\end{array}$ \\
\hline $\begin{array}{l}\text { FnBPA+ } \\
\text { (pValac:ESAT-6) }\end{array}$ & Recombinant & BCG booster vaccine & $\begin{array}{l}\text { Pereira, V.B., } \\
\text { et al. [65] }\end{array}$ \\
\hline $\begin{array}{l}\text { M. smegmatis expressing } \\
\text { Ag85B }\end{array}$ & Recombinant & $\begin{array}{l}\text { Recombinant bacterium } \\
\text { study to evaluate } \\
\text { immunogenicity }\end{array}$ & Kadir, et al. [66] \\
\hline ChAdOx/MVA PPE15 & Recombinant & Viral recombinant & $\begin{array}{l}\text { Stockdale, L. } \\
\text { \& Fletcher, H. [13] }\end{array}$ \\
\hline CMV-6Ag & Recombinant & $\begin{array}{l}\text { Contains ESAT-6, Ag85A, } \\
\text { Ag85B, Rv3407; Rv1733; } \\
\text { Rv2626, Rpf A, Rpf C, rpf } \\
\text { D }\end{array}$ & $\begin{array}{l}\text { Stockdale, L. } \\
\text { \& Fletcher, H. [13] }\end{array}$ \\
\hline
\end{tabular}

Several live viral-vector based vaccines have also entered into clinical trials (Table 2). The MVA85A vaccine, also known as AERAS-485, is currently being evaluated in two phase 2a trials (Table 2). One other vaccine is in phase $2 \mathrm{a}$, and five vaccines are currently being evaluated in phase 1 studies (Table 2). In general, live viral-vector based vaccines have advantages for safety and ease of production but have the disadvantage of gene expression instability [32].

\section{Recombinant Vaccine Candidates Using M. tuberculosis-Specific Antigens}

The above stated recombinant DNA vaccines undergoing clinical trials are based on cross-reactive antigens of $M$. tuberculosis. These antigens may have the same problem of false positivity as BCG, with respect to the diagnosis of TB using PPD. Furthermore, because of the cross-reactivity with environmental mycobacteria, these candidate vaccines may face the problem of masking or blocking effects and may not be useful as booster vaccines in BCG pre-vaccinated individuals [67]. According to the masking hypothesis, early sensitization with environmental mycobacteria confers some level of protection against TB that masks the effect of a vaccine given later in life due to the presence of cross-reactive antigens. The blocking hypothesis postulates that previous immune responses to cross-reactive antigens, because of environmental mycobacteria sensitization, prevents the taking of a new vaccine by efficient clearance of the new vaccine antigens [67]. The use of $M$. tuberculosis-specific antigens as new TB vaccines may overcome these problems of blocking or masking. Therefore, to have $\mathrm{TB}$ vaccines better than $\mathrm{BCG}$, development of new subunit and/or recombinant vaccines based on M. tuberculosis-specific antigens is required and is currently in progress [68]. Although three $M$. tuberculosis-specific regions known as regions of differences (RD) were identified using classical molecular and biochemical techniques, the identification of all M. tuberculosis-specific regions was possible with advances in whole genome sequencing and the comparative genome analysis of M. tuberculosis with other mycobacterial genomes [69]. These RDs are deleted/absent in all BCG sub-strains currently under use in different parts of the world [69]. The computer-based analysis for open reading frames has suggested that these RDs can potentially encode a large number of antigenic proteins [70]. To identify the candidate proteins suitable for vaccine development, these proteins were first tested for their ability to induce cellular immune responses in vitro with cells from naturally infected animals and humans. Such experiments with peripheral blood cells from humans and cattle identified six antigens inducing strong cellular immune responses i.e., PE35, PPE68, ESAT-6, CFP10, Rv3619c, and Rv2346c [71,72]. Testing of these antigens in animal models of TB have shown that all of these antigens are capable of inducing Th1 responses when used in combination with appropriate adjuvants and delivery systems such as DNA vaccine vectors and non-pathogenic mycobacteria, including BCG [73-77]. In mice and guinea pigs, immunizations with ESAT-6, CFP-10, and Rv3619c resulted into protection against challenges with $M t b$ [78-80]. 
In humans, a recombinant subunit TB vaccine candidate, GamTBvac, which contains a dextran-binding domain modified Ag85a and M. tuberculosis-specific antigens ESAT6-CFP10 with an adjuvant has been tested in a phase I clinical trial [81]. Safety and immunogenicity of GamTBvac were determined in healthy volunteers previously vaccinated with BCG. The GamTBvac reached an acceptable safety profile and was tolerated well. Furthermore, the immunization protocols led to a significant increase in the concentration of the protective Th1-cytokine IFN- $\gamma$ and IgG antibodies. The immune responses were induced to all three antigens included in GamTBvac [81]. This vaccine has moved to a phase 2a clinical trial in humans (Table 1). Another recombinant bacterial vaccine in the preclinical stage and based on $M$. tuberculosis-specific ESAT-6 antigen is L. lactis FnBPA+ (pValac:ESAT-6). When delivered by mucosal route, this vaccine produced a systemic Th1 cell response and significant increase in specific secretory immunoglobulin A production in colon tissue and fecal extracts [82]. In a booster model of mice preimmunized with BCG, this vaccine induced a significant increase in proinflammatory cytokines IL-17, IFN- $\gamma$, IL-6, and TNF- $\alpha$ from spleens of immunized mice [65]. These findings are novel because they represent the first successful step towards the development of an oral booster to the BCG vaccine by using a $M$. tuberculosis-specific antigen with a bacteria L. lactis as a DNA delivery system.

\section{Routes of Vaccine Administration}

BCG is administered intradermally, where it induces a strong systemic response but weak mucosal immune response [83]. This presents a challenge since Mtb is transmitted via the respiratory route. Although the effects of different routes of administration are not readily discussed in the literature, some studies have shown that an alternative route may be a better possibility for the administration of $\mathrm{Mtb}$ vaccines. The oral vs intradermal administration of BCG was evaluated in a small trial, and the results showed that oral BCG produced a stronger mucosal response in bronchoalveolar lavage cells in nasal washes and tears, although intradermal BCG produced a stronger response in the blood [84]. In another study, intravenous administration of BCG vaccines in rhesus macaques produced an increased $\mathrm{T}$ cell response and induced a large population of $\mathrm{T}$ cells in the lungs, showing much protective promise [85]. Additional routes used in subunit vaccine administration include subcutaneous and intranasal [83], edible, mucosal, and nanoparticle-based vaccines [9]. Edible-based strategies employ the use of antigens expressed in plants such as carrot, potato, tobacco, and Lemna minor to activate the immune response [9], and nanoparticle strategies use nanoparticles conjugated with antigens such as Ag85B to increase Th1 responses in lymphoid organs against Mtb [9]. However, an optimal route for $\mathrm{Mtb}$ vaccine administration is yet to be identified. Hence, additional work is required to identify a route of vaccine administration that provides maximum protection against infection with $\mathrm{Mtb}$.

\section{Summary}

TB is an ancient disease with worldwide prevalence, but only one licensed vaccine, BCG, is available for use with many concerns. Hence, sincere efforts are being made globally for the development of improved vaccines against TB. Among the strategies to develop new TB vaccines, whole-cell mycobacteria, subunit, and recombinant vaccine strategies have been employed. These efforts have led to the identification of about two dozen vaccine candidates currently in the pipeline at different stages of clinical trials in humans. Furthermore, additional TB vaccine candidates are at the preclinical stage and are being tested in animal models of TB. The progress made for the development of improved vaccines against TB is highly encouraging and it is hoped that new licensed TB vaccines for preventive and therapeutic applications in humans may become a reality in the near future.

Author Contributions: Conceptualization, S.N.M.H.; E.W.; writing-original draft preparation, A.S.M.; writing-review and editing. All authors have read and agreed to the published version of the manuscript.

Funding: This research received no external funding.

Conflicts of Interest: The authors declare no conflict of interest. 


\section{References}

1. World Health Organization. Tuberculosis. Available online: https:/www.who.int/news-room/fact-sheets/ detail/tuberculosis (accessed on 16 August 2020).

2. Houben, R.M.; Dodd, P.J. The Global Burden of Latent Tuberculosis Infection: A Re-estimation Using Mathematical Modelling. PLoS Med. 2016, 13, e1002152. [CrossRef] [PubMed]

3. Mustafa, A.S. BCG pros and cons and new/improved vaccines for tuberculosis. In Text Book of Biochemistry, Biotechnology, Allied and Molecular Medicine, 4th ed.; Talwar, G.P., Hasnain, S.E., Sarin, S.K., Hasnain, S., Eds.; PHI Learning Private Limited: Delhi, India, 2016; Chapter 117; pp. 1347-1353.

4. Singh, V.K.; Srivastava, R.; Srivastava, B.S. Manipulation of BCG vaccine: A double-edged sword. Eur. J. Clin. Microbiol. Infect. Dis. 2016, 35, 535-543. [CrossRef] [PubMed]

5. Roy, P.; Vekemans, J.; Clark, A.; Sanderson, C.; Harris, R.C.; White, R.G. Potential effect of age of BCG vaccination on global paediatric tuberculosis mortality: A modelling study. Lancet Glob. Health 2019, 7, e1655-e1663. [CrossRef]

6. Mangtani, P.; Abubakar, I.; Ariti, C.; Beynon, R.; Pimpin, L.; Fine, P.E.; Rodrigues, L.C.; Smith, P.G.; Lipman, M.; Whiting, P.F.; et al. Protection by BCG vaccine against tuberculosis: A systematic review of randomized controlled trials. Clin. Infect. Dis. 2014, 58, 470-480. [CrossRef]

7. Abubakar, I.; Pimpin, L.; Ariti, C.; Beynon, R.; Mangtani, P.; Sterne, J.A.; Fine, P.E.; Smith, P.G.; Lipman, M.; Elliman, D.; et al. Systematic review and meta-analysis of the current evidence on the duration of protection by bacillus Calmette-Guérin vaccination against tuberculosis. Health Technol. Assess. 2013, 17, 1-372. [CrossRef] [PubMed]

8. Fatima, S.; Kumari, A.; Das, G.; Dwivedi, V.P. Tuberculosis vaccine: A journey from BCG to present. Life Sci. 2020, 252, 117594. [CrossRef] [PubMed]

9. Yadav, J.; Verma, S.; Chaudhary, D.; Jaiwal, P.K.; Jaiwal, R. Tuberculosis: Current Status, Diagnosis, Treatment and Development of Novel Vaccines. Curr. Pharm. Biotechnol. 2019, 20, 446-458. [CrossRef] [PubMed]

10. Al-Rifai, R.H.; Pearson, F.; Critchley, J.A.; Abu-Raddad, L.J. Association between diabetes mellitus and active tuberculosis: A systematic review and meta-analysis. PLoS ONE 2017, 12, e0187967. [CrossRef]

11. Kewcharoenwong, C.; Saenwongsa, W.; Willcocks, S.J.; Bancroft, G.J.; Fletcher, H.A.; Lertmemongkolchai, G. Glibenclamide alters interleukin- 8 and interleukin- $1 \beta$ of primary human monocytes from diabetes patients against Mycobacterium tuberculosis infection. Tuberculosis 2020, 123, 101939. [CrossRef]

12. Mustafa, A.S. Vaccine potential of mycobacterial antigens against asthma. Med. Princ. Pract. 2020, 29, 404-411. [CrossRef]

13. Stockdale, L.; Fletcher, H. The Future of Vaccines for Tuberculosis. Clin. Chest Med. 2019, 40, 849-856. [CrossRef] [PubMed]

14. World Health Organization. BCG vaccine: WHO position paper, February 2018-Recommendations. Vaccine 2018, 36, 3408-3410. [CrossRef] [PubMed]

15. Méndez-Samperio, P. Current challenges and opportunities for bacillus Calmette-Guérin replacement vaccine candidates. Scand. J. Immunol. 2019, 90, e12772. [CrossRef] [PubMed]

16. Ragonnet, R.; Trauer, J.M.; Geard, N.; Scott, N.; McBryde, E.S. Profiling Mycobacterium tuberculosis transmission and the resulting disease burden in the five highest tuberculosis burden countries. BMC Med. 2019, 17, 208. [CrossRef] [PubMed]

17. Dockrell, H.M.; Smith, S.G. What Have We Learnt about BCG Vaccination in the Last 20 Years? Front. Immunol. 2017, 8, 1134. [CrossRef]

18. Fekrvand, S.; Yazdani, R.; Olbrich, P.; Gennery, A.; Rosenzweig, S.D.; Condino-Neto, A.; Azizi, G.; Rafiemanesh, H.; Hassanpour, G.; Rezaei, N.; et al. Primary Immunodeficiency Diseases and Bacillus Calmette-Guérin (BCG)-Vaccine-Derived Complications: A Systematic Review. J. Allergy Clin. Immunol. Pract. 2020, 8, 1371-1386. [CrossRef]

19. Mazzola, T.N.; da Silva, M.T.; Abramczuk, B.M.; Moreno, Y.M.; Lima, S.C.; Zorzeto, T.Q.; Passeto, A.S.; Vilela, M.M. Impaired Bacillus Calmette-Guérin cellular immune response in HIV-exposed, uninfected infants. Aids 2011, 25, 2079-2087. [CrossRef]

20. Pahal, P.; Sharma, S. PPD Skin Test (Tuberculosis Skin Test). In StatPearls; StatPearls Publishing: Treasure Island, FL, USA, 2020. 
21. World Health Organization. End TB Strategy. 2019. Available online: https://www.who.int/tb/strategy/en/ (accessed on 16 August 2020).

22. Kasempimolporn, S.; Areekul, P.; Thaveekarn, W.; Sutthisri, R.; Boonchang, S.; Sawangvaree, A.; Sitprija, V. Application of transdermal patches with new skin test reagents for detection of latent tuberculosis. J. Med. Microbiol. 2019, 68, 1314-1319. [CrossRef]

23. Basaraba, R.J.; Hunter, R.L. Pathology of Tuberculosis: How the Pathology of Human Tuberculosis Informs and Directs Animal Models. Microbiol. Spectr. 2017, 5. [CrossRef]

24. Zhu, B.; Dockrell, H.M.; Ottenhoff, T.H.M.; Evans, T.G.; Zhang, Y. Tuberculosis vaccines: Opportunities and challenges. Respirology 2018, 23, 359-368. [CrossRef]

25. Satti, I.; McShane, H. Current approaches toward identifying a correlate of immune protection from tuberculosis. Expert Rev. Vaccines 2019, 18, 43-59. [CrossRef] [PubMed]

26. Bhatt, K.; Verma, S.; Ellner, J.J.; Salgame, P. Quest for correlates of protection against tuberculosis. Clin. Vaccine Immunol. 2015, 22, 258-266. [CrossRef]

27. Pipeline of Vaccines. Available online: https://www.tbvi.eu/what-we-do/pipeline-of-vaccines/ (accessed on 16 August 2020).

28. Gupta, N.; Garg, S.; Vedi, S.; Kunimoto, D.Y.; Kumar, R.; Agrawal, B. Future Path Toward TB Vaccine Development: Boosting BCG or Re-educating by a New Subunit Vaccine. Front. Immunol. 2018, 9, 2371. [CrossRef] [PubMed]

29. Kuczkowska, K.; Copland, A.; Øverland, L.; Mathiesen, G.; Tran, A.C.; Paul, M.J.; Eijsink, V.G.H.; Reljic, R. Inactivated Lactobacillus plantarum Carrying a Surface-Displayed Ag85B-ESAT-6 Fusion Antigen as a Booster Vaccine Against Mycobacterium tuberculosis Infection. Front. Immunol. 2019, 10, 1588. [CrossRef]

30. Platteel, A.C.M.; Nieuwenhuizen, N.E.; Domaszewska, T.; Schürer, S.; Zedler, U.; Brinkmann, V.; Sijts, A.; Kaufmann, S.H.E. Efficacy Testing of H56 cDNA Tattoo Immunization against Tuberculosis in a Mouse Model. Front. Immunol. 2017, 8, 1744. [CrossRef]

31. Bourinbaiar, A.S.; Batbold, U.; Efremenko, Y.; Sanjagdorj, M.; Butov, D.; Damdinpurev, N.; Grinishina, E.; Mijiddorj, O.; Kovolev, M.; Baasanjav, K.; et al. Phase III, placebo-controlled, randomized, double-blind trial of tableted, therapeutic TB vaccine (V7) containing heat-killed M. vaccae administered daily for one month. J. Clin. Tuberc. Other Mycobact. Dis. 2019, 18, 100141. [CrossRef] [PubMed]

32. Vetter, V.; Denizer, G.; Friedland, L.R.; Krishnan, J.; Shapiro, M. Understanding modern-day vaccines: What you need to know. Ann. Med. 2018, 50, 110-120. [CrossRef]

33. Gonzalo-Asensio, J.; Marinova, D.; Martin, C.; Aguilo, N. MTBVAC: Attenuating the Human Pathogen of Tuberculosis (TB) Toward a Promising Vaccine against the TB Epidemic. Front. Immunol. 2017, 8, 1803. [CrossRef]

34. Pérez, I.; Uranga, S.; Sayes, F.; Frigui, W.; Samper, S.; Arbués, A.; Aguiló, N.; Brosch, R.; Martín, C.; Gonzalo-Asensio, J. Live attenuated TB vaccines representing the three modern Mycobacterium tuberculosis lineages reveal that the Euro-American genetic background confers optimal vaccine potential. EBioMedicine 2020, 55, 102761. [CrossRef]

35. Broset, E.; Saubi, N.; Guitart, N.; Aguilo, N.; Uranga, S.; Kilpeläinen, A.; Eto, Y.; Hanke, T.; Gonzalo-Asensio, J.; Martín, C.; et al. MTBVAC-Based TB-HIV Vaccine Is Safe, Elicits HIV-T Cell Responses, and Protects against Mycobacterium tuberculosis in Mice. Mol. Ther. Methods Clin. Dev. 2019, 13, 253-264. [CrossRef]

36. Gong, W.; Liang, Y.; Wu, X. The current status, challenges, and future developments of new tuberculosis vaccines. Hum. Vaccines Immunother. 2018, 14, 1697-1716. [CrossRef] [PubMed]

37. Pennisi, M.; Russo, G.; Sgroi, G.; Bonaccorso, A.; Parasiliti Palumbo, G.A.; Fichera, E.; Mitra, D.K.; Walker, K.B.; Cardona, P.J.; Amat, M.; et al. Predicting the artificial immunity induced by RUTI ${ }^{\circledR}$ vaccine against tuberculosis using universal immune system simulator (UISS). BMC Bioinform. 2019, 20, 504. [CrossRef] [PubMed]

38. Huang, C.Y.; Hsieh, W.Y. Efficacy of Mycobacterium vaccae immunotherapy for patients with tuberculosis: A systematic review and meta-analysis. Hum. Vaccines Immunother. 2017, 13, 1960-1971. [CrossRef]

39. Cardona, P.J. The Progress of Therapeutic Vaccination with Regard to Tuberculosis. Front. Microbiol. 2016, 7, 1536. [CrossRef]

40. Prabowo, S.A.; Painter, H.; Zelmer, A.; Smith, S.G.; Seifert, K.; Amat, M.; Cardona, P.J.; Fletcher, H.A. RUTI Vaccination Enhances Inhibition of Mycobacterial Growth ex vivo and Induces a Shift of Monocyte Phenotype in Mice. Front. Immunol. 2019, 10, 894. [CrossRef] 
41. Teitelbaum, R.; Schubert, W.; Gunther, L.; Kress, Y.; Macaluso, F.; Pollard, J.W.; McMurray, D.N.; Bloom, B.R. The $\mathrm{M}$ cell as a portal of entry to the lung for the bacterial pathogen Mycobacterium tuberculosis. Immunity 1999, 10, 641-650. [CrossRef]

42. Liu, L.; Zhang, W.J.; Zheng, J.; Fu, H.; Chen, Q.; Zhang, Z.; Chen, X.; Zhou, B.; Feng, L.; Liu, H.; et al. Exploration of novel cellular and serological antigen biomarkers in the ORFeome of Mycobacterium tuberculosis. Mol. Cell. Proteom. 2014, 13, 897-906. [CrossRef] [PubMed]

43. Yan, Y.H.; Li, M.C.; Liu, H.C.; Xiao, T.Y.; Li, N.; Lou, Y.L.; Wan, K.L. Cellular immunity evaluation of five mycobacterium tuberculosis recombinant proteins and their compositions. Zhonghua Yu Fang Yi Xue Za Zhi 2020, 54, 539-545. [CrossRef]

44. Ong, E.; He, Y.; Yang, Z. Epitope promiscuity and population coverage of Mycobacterium tuberculosis protein antigens in current subunit vaccines under development. Infect. Genet. Evol. 2020, 80, 104186. [CrossRef]

45. Kim, A.; Hur, Y.G.; Gu, S.; Cho, S.N. Protective Vaccine Efficacy of the Complete Form of PPE39 Protein from Mycobacterium tuberculosis Beijing/K Strain in Mice. Clin. Vaccine Immunol. 2014, 24, e00219-17. [CrossRef]

46. Hanafiah, K.M.; Arifin, N.; Sanders, P.R.; Othman, N.; Garcia, M.L.; Anderson, D.A. Proteomic Analysis of Antigen 60 Complex of M. bovis Bacillus Calmette-Guérin Reveals Presence of Extracellular Vesicle Proteins and Predicted Functional Interactions. Vaccines 2019, 7, 80. [CrossRef] [PubMed]

47. Moguche, A.O.; Musvosvi, M.; Penn-Nicholson, A.; Plumlee, C.R.; Mearns, H.; Geldenhuys, H.; Smit, E.; Abrahams, D.; Rozot, V.; Dintwe, O.; et al. Antigen Availability Shapes T Cell Differentiation and Function during Tuberculosis. Cell Host Microbe 2017, 21, 695-706. [CrossRef] [PubMed]

48. Thakur, A.; Pinto, F.E.; Hansen, H.S.; Andersen, P.; Christensen, D.; Janfelt, C.; Foged, C. Intrapulmonary (i.pulmon.) Pull Immunization with the Tuberculosis Subunit Vaccine Candidate H56/CAF01 after Intramuscular (i.m.) Priming Elicits a Distinct Innate Myeloid Response and Activation of Antigen-Presenting Cells Than i.m. or i.pulmon. Prime Immunization Alone. Front. Immunol. 2020, 11, 803. [CrossRef] [PubMed]

49. Marasini, N.; Kaminskas, L.M. Subunit-based mucosal vaccine delivery systems for pulmonary delivery Are they feasible? Drug Dev. Ind. Pharm. 2019, 45, 882-894. [CrossRef]

50. Liu, X.; Da, Z.; Wang, Y.; Niu, H.; Li, R.; Yu, H.; He, S.; Guo, M.; Luo, Y.; Ma, X.; et al. A novel liposome adjuvant DPC mediates Mycobacterium tuberculosis subunit vaccine well to induce cell-mediated immunity and high protective efficacy in mice. Vaccine 2016, 34, 1370-1378. [CrossRef]

51. Nemes, E.; Geldenhuys, H.; Rozot, V.; Rutkowski, K.T.; Ratangee, F.; Bilek, N.; Mabwe, S.; Makhethe, L.; Erasmus, M.; Toefy, A.; et al. Prevention of M. tuberculosis Infection with H4:IC31 Vaccine or BCG Revaccination. N. Engl. J. Med. 2018, 379, 138-149. [CrossRef]

52. White, R.G.; Hanekom, W.A.; Vekemans, J.; Harris, R.C. The way forward for tuberculosis vaccines. Lancet Respir. Med. 2019, 7, 204-206. [CrossRef]

53. Rodo, M.J.; Rozot, V.; Nemes, E.; Dintwe, O.; Hatherill, M.; Little, F.; Scriba, T.J. A comparison of antigen-specific $\mathrm{T}$ cell responses induced by six novel tuberculosis vaccine candidates. PLoS Pathog. 2019, 15, e1007643. [CrossRef]

54. Recombinant Vaccine. 2020. Available online: https://www.nature.com/subjects/recombinant-vaccine (accessed on 1 July 2020).

55. Nascimento, I.P.; Leite, L.C. Recombinant vaccines and the development of new vaccine strategies. Braz. J. Med. Biol. Res. 2012, 45, 1102-1111. [CrossRef]

56. Da Costa, A.C.; Nogueira, S.V.; Kipnis, A.; Junqueira-Kipnis, A.P. Recombinant BCG: Innovations on an Old Vaccine. Scope of BCG Strains and Strategies to Improve Long-Lasting Memory. Front. Immunol. 2014, 5, 152. [CrossRef]

57. Kilpeläinen, A.; Saubi, N.; Guitart, N.; Olvera, A.; Hanke, T.; Brander, C.; Joseph, J. Recombinant BCG Expressing HTI Prime and Recombinant ChAdOx1 Boost Is Safe and Elicits HIV-1-Specific T-Cell Responses in BALB/c Mice. Vaccines 2019, 7, 78. [CrossRef] [PubMed]

58. Mancha-Agresti, P.; de Castro, C.P.; Dos Santos, J.; Araujo, M.A.; Pereira, V.B.; LeBlanc, J.G.; Leclercq, S.Y.; Azevedo, V. Recombinant Invasive Lactococcus lactis Carrying a DNA Vaccine Coding the Ag85A Antigen Increases IFN- $\gamma$, IL-6, and TNF-A- $\alpha$ Cytokines after Intranasal Immunization. Front. Microbiol. 2017, 8, 1263. [CrossRef] [PubMed]

59. Kaushik, A.; Ammerman, N.C.; Tyagi, S.; Saini, V.; Vervoort, I.; Lachau-Durand, S.; Nuermberger, E.; Andries, K. Activity of a Long-Acting Injectable Bedaquiline Formulation in a Paucibacillary Mouse Model of Latent Tuberculosis Infection. Antimicrob. Agents Chemother. 2019, 63, e00007-19. [CrossRef] [PubMed] 
60. Asai, M.; Li, Y.; Spiropoulos, J.; Cooley, W.; Everest, D.; Robertson, B.D.; Langford, P.R.; Newton, S.M. A novel biosafety level 2 compliant tuberculosis infection model using a $\Delta$ leuD $\Delta$ panCD double auxotroph of Mycobacterium tuberculosis H37Rv and Galleria mellonella. Virulence 2020, 11, 811-824. [CrossRef] [PubMed]

61. Counoupas, C.; Pinto, R.; Nagalingam, G.; Britton, W.J.; Petrovsky, N.; Triccas, J.A. Delta inulin-based adjuvants promote the generation of polyfunctional CD4+ $\mathrm{T}$ cell responses and protection against Mycobacterium tuberculosis infection. Sci. Rep. 2017, 7, 8582. [CrossRef]

62. Yan, Q.; Liu, H.; Cheng, Z.; Xue, Y.; Dai, X.; Shan, W.; Chen, F. Immunotherapeutic effect of BCG-polysaccharide nucleic acid powder on Mycobacterium tuberculosis-infected mice using microneedle patches. Drug Deliv. 2017, 24, 1648-1653. [CrossRef]

63. Liu, X.; Peng, J.; Hu, L.; Luo, Y.; Niu, H.; Bai, C.; Wang, Q.; Li, F.; Yu, H.; Wang, B.; et al. A multistage mycobacterium tuberculosis subunit vaccine LT70 including latency antigen Rv2626c induces long-term protection against tuberculosis. Hum. Vaccines Immunother. 2016, 12, 1670-1677. [CrossRef]

64. Carvalho Dos Santos, C.; Rodriguez, D.; Kanno Issamu, A.; Cezar De Cerqueira Leite, L.; Pereira Nascimento, I. Recombinant BCG expressing the LTAK63 adjuvant induces increased early and long-term immune responses against Mycobacteria. Hum. Vaccines Immunother. 2020, 16, 673-683. [CrossRef]

65. Pereira, V.B.; da Cunha, V.P.; Preisser, T.M.; Souza, B.M.; Turk, M.Z.; De Castro, C.P.; Azevedo, M.; Miyoshi, A. Lactococcus lactis carrying a DNA vaccine coding for the ESAT-6 antigen increases IL-17 cytokine secretion and boosts the BCG vaccine immune response. J. Appl. Microbiol. 2017, 122, 1657-1662. [CrossRef]

66. Kadir, N.A.; Sarmiento, M.E.; Acosta, A.; Norazmi, M.N. Cellular and humoral immunogenicity of recombinant Mycobacterium smegmatis expressing Ag85B epitopes in mice. Int. J. Mycobacteriol. 2016, 5, 7-13. [CrossRef]

67. Arregui, S.; Sanz, J.; Marinova, D.; Martín, C.; Moreno, Y. On the impact of masking and blocking hypotheses for measuring the efficacy of new tuberculosis vaccines. Peer J. 2016, 4, e1513. [CrossRef]

68. Mustafa, A.S. Plasmid DNA and mycobacteria as antigen delivery systems for Mycobacterium tuberculosis-specific antigens. In Chapter in Molecular Medicine: Bench to Bedside and Beyond; Gupta, S.K., Lohiya, N.K., Eds.; Indian Society for the Study of Reproduction and Fertility, University of Rajasthan: Jaipur, India, 2018; pp. 244-252.

69. Mustafa, A.S. Mycobacterial gene cloning and expression, comparative genomics, bioinformatics and proteomics in relation to the development of new vaccines and diagnostic reagents. Med. Princ. Pract. 2005, 14, 27-34. [CrossRef]

70. Mustafa, A.S. Development of new vaccines and diagnostic reagents against tuberculosis. Mol. Immunol. 2002, 39, 113-119. [CrossRef]

71. Mustafa, A.S.; Al-Attiyah, R.; Hanif, S.N.; Shaban, F.A. Efficient testing of large pools of Mycobacterium tuberculosis RD1 peptides and identification of major antigens and immunodominant peptides recognized by human Th1 cells. Clin. Vaccine Immunol. 2008, 15, 916-924. [CrossRef] [PubMed]

72. Mustafa, A.S. In silico analysis and experimental validation of Mycobacterium tuberculosis-specific proteins and peptides of Mycobacterium tuberculosis for immunological diagnosis and vaccine development. Med. Princ. Pract. 2013, 22, 43-51. [CrossRef] [PubMed]

73. Hanif, S.N.M.; Al-Attiyah, R.; Mustafa, A.S. DNA vaccine constructs expressing Mycobacterium tuberculosis-specific genes induce immune responses. Scand. J. Immunol. 2010, 72, 408-415. [CrossRef]

74. Hanif, S.N.; Al-Attiyah, R.; Mustafa, A.S. Cellular immune responses in mice induced by M. tuberculosis PE35-DNA vaccine construct. Scand. J. Immunol. 2011, 74, 554-560. [CrossRef]

75. Shaban, K.; Amoudy, H.A.; Mustafa, A.S. Cellular immune responses to recombinant Mycobacterium bovis BCG constructs expressing major antigens of region of difference 1 of Mycobacterium tuberculosis. Clin. Vaccine Immunol. 2013, 20, 1230-1237. [CrossRef]

76. Amoudy, H.A.; Ebrahimi, B.H.; Mustafa, A.S. Immune responses against Mycobacterium tuberculosis-specific proteins PE35 and CFP10 in mice immunized with recombinant Mycobacterium vaccae. Saudi Med. J. 2014, 35, 350-359.

77. Safar, H.A.; Mustafa, A.S.; Amoudy, H.A.; El-Hashim, A. The effect of adjuvants and delivery systems on Th1, Th2, Th17 and Treg cytokine responses in mice immunized with Mycobacterium tuberculosis-specific proteins. PLoS ONE 2020, 15, e0228381. [CrossRef] 
78. Ansari, M.A.; Zubair, S.; Mahmood, A.; Gupta, P.; Khan, A.A.; Gupta, U.D.; Arora, A.; Owais, M. RD antigen based nanovaccine imparts long term protection by inducing memory response against experimental murine tuberculosis. PLoS ONE 2011, 6, e22889. [CrossRef] [PubMed]

79. Tkachuk, A.P.; Gushchin, V.A.; Potapov, V.D.; Demidenko, A.V.; Lunin, V.G.; Gintsburg, A.L. Multi-subunit BCG booster vaccine GamTBvac: Assessment of immunogenicity and protective efficacy in murine and guinea pig TB models. PLoS ONE 2017, 12, e0176784. [CrossRef] [PubMed]

80. Wang, C.; Lu, J.; Du, W.; Wang, G.; Li, X.; Shen, X.; Su, C.; Yang, L.; Chen, B.; Wang, J.; et al. Ag85b/ESAT6-CFP10 adjuvanted with aluminum/poly-IC effectively protects guinea pigs from latent Mycobacterium tuberculosis infection. Vaccine 2019, 37, 4477-4484. [CrossRef]

81. Vasina, D.V.; Kleymenov, D.A.; Manuylov, V.A.; Mazunina, E.P.; Koptev, E.Y.; Tukhovskaya, E.A.; Murashev, A.N.; Gintsburg, A.L.; Gushchin, V.A.; Tkachuk, A.P. First-In-Human Trials of GamTBvac, a Recombinant Subunit Tuberculosis Vaccine Candidate: Safety and Immunogenicity Assessment. Vaccines 2019, 7, 166. [CrossRef] [PubMed]

82. Pereira, V.B.; Saraiva, T.D.; Souza, B.M.; Zurita-Turk, M.; Azevedo, M.S.; De Castro, C.P.; Mancha-Agresti, P.; Dos Santos, J.S.; Santos, A.C.; Faria, A.M.; et al. Development of a new DNA vaccine based on mycobacterial ESAT-6 antigen delivered by recombinant invasive Lactococcus lactis FnBPA+. Appl. Microbiol. Biotechnol. 2015, 99, 1817-1826. [CrossRef]

83. Gupta, N.; Vedi, S.; Kunimoto, D.Y.; Agrawal, B.; Kumar, R. Novel lipopeptides of ESAT-6 induce strong protective immunity against Mycobacterium tuberculosis: Routes of immunization and TLR agonists critically impact vaccine's efficacy. Vaccine 2016, 34, 5677-5688. [CrossRef]

84. Hoft, D.F.; Xia, M.; Zhang, G.L.; Blazevic, A.; Tennant, J.; Kaplan, C.; Matuschak, G.; Dube, T.J.; Hill, H.; Schlesinger, L.S.; et al. PO and ID BCG vaccination in humans induce distinct mucosal and systemic immune responses and $\mathrm{CD}^{+}{ }^{+} \mathrm{T}$ cell transcriptomal molecular signatures. Mucosal Immunol. 2018, 11, 486-495. [CrossRef] [PubMed]

85. Darrah, P.A.; Zeppa, J.J.; Maiello, P.; Hackney, J.A.; Wadsworth, M.H., 2nd; Hughes, T.K.; Pokkali, S.; Swanson, P.A., 2nd; Grant, N.L.; Rodgers, M.A.; et al. Prevention of tuberculosis in macaques after intravenous BCG immunization. Nature 2020, 577, 95-102. [CrossRef] 